\title{
Modified Frailty Index to Assess Risk in Elderly Patients Undergoing Distal Pancreatectomy: A Retrospective Single- Center Study
}

\author{
Salvatore Paiella ${ }^{1}$ Matteo De Pastena ${ }^{1} \cdot$ Alessandro Esposito $^{1,2} \cdot$ Erica Secchettin $^{1}$ • \\ Luca Casetti $^{1}$ - Giuseppe Malleo $^{1} \cdot$ Greta Montagnini $^{1} \cdot$ Elisa Bannone $^{1} \cdot$ Giacomo Deiro $^{1}$. \\ Beatrice Bampa ${ }^{1} \cdot$ Marco Ramera $^{1} \cdot$ Luca Landoni $^{1} \cdot$ Alberto Balduzzi $^{1}$ - Claudio Bassi ${ }^{1}$. \\ Roberto Salvia ${ }^{1}$
}

Accepted: 10 December 2021/Published online: 13 January 2022

(C) The Author(s) 2022

\begin{abstract}
Background To compare the postoperative course of elderly patients ( $\geq 70$ years) submitted to minimally invasive (MIDP) versus open distal pancreatectomy (ODP) and to evaluate if the modified Frailty Index (mFI) predicts the surgical course of elderly patients submitted to DP.

Methods Data of patients aged $\geq 70$ who underwent DP at a single institution between March 2011 and December 2019 were retrospectively retrieved. A 2:1 propensity score matching (PSM) was used to correct for differences in baseline characteristics. Then, postoperative complications were compared between the two groups (MIDP vs. ODP). Additionally, the entire cohort of DP elderly patients was stratified according to the $\mathrm{mFI}$ into three groups: non-frail $(\mathrm{mFI}=0)$, mildly frail $(\mathrm{mFI}=1 / 2)$, or severely frail $(\mathrm{mFI}=3)$ and then compared.

Results A total of 204 patients were analyzed. After PSM, 40 MIDP and 80 ODP patients were identified. The complications considered stratified homogenously between the two groups, with no statistically significant differences. The severity of the postoperative course increased as mFI did among the three groups regarding any complication $(p=0.022)$, abdominal collection $(p=0.014)$, pulmonary complication $(p=0.001)$, postoperative confusion $(p=0.047)$, Clavien-Dindo severity $\geq 3$ events $(p=0.036)$, and length of stay $(p=0.018)$.

Conclusions Elderly patients can be safely submitted to MIDP. The mFI identifies frail elderly patients more prone to develop surgical and non-surgical complications after DP.
\end{abstract}

The results of this study have been partially presented at the European Association for Endoscopic Surgery Congress, November 2021, Barcelona, Spain.

Alessandro Esposito

alessandro.esposito@aovr.veneto.it

Matteo De Pastena

matteo.depastena@aovr.veneto.it

1 General and Pancreatic Surgery Unit, Pancreas Institute, University of Verona Hospital, Verona, Italy

2 Referent of the Mini-Invasive Pancreatic Laparoscopic and Robotic Surgery of the General and Pancreatic Surgery Unit, Department of General and Pancreatic Surgery, The Pancreas Institute, University of Verona Hospital Trust, P.le Scuro 10, 37134 Verona, Italy

\section{Introduction}

Minimally invasive distal pancreatectomy (MIDP) is gaining favor over open distal pancreatectomy (ODP) to treat the pancreas' body-tail neoplasms [1]. An international cohort study showed less major morbidity after MIDP, with predicted better outcomes as the conversion rate decreases following the implementation of the technique $[2,3]$.

Thanks to intervention in health, political, and socioeconomic aspects, lifespan, and healthspan are expected to increase in the next decades [4,5], at least in developed countries. This scenario and the incidence of pancreatic tumors that increase with age-with a mean age of 70 years [5] - are responsible for the frequent facing with elderly 
patients by pancreatic surgeons. Current literature reports controversial results regarding the impact of advanced age on surgical outcomes after pancreatic surgery. In 2012, a meta-analysis reported that elderly patients experience higher rates of postoperative complications and mortality [6]. Other manuscripts, afterward, found that pancreatic surgery has similar safety and efficacy profiles in elderly versus non-elderly [7-10]. Regarding minimally invasive pancreaticoduodenectomy, data analysis on 1768 elderly patients submitted to laparoscopic versus open pancreaticoduodenectomy from the United States National Cancer Dabatase showed that minimally invasive cases experience lower mortality rates [11]. Few manuscripts have compared MIDP versus ODP in elderly patients. In particular, four retrospective, non-case-matched studies, enrolling a total of 248 patients, reported that MIDP has the same safety profile that ODP in elderly patients [12-14] and that some postoperative outcomes, such as confusion, length of stay, and intraoperative blood loss, are even better for MIDP [15]. Certainly, there is a proper patient selection beyond these surgical cohorts, so maybe the fittest ones were chosen. A recent meta-analysis pooled the results of these studies and confirmed the conclusions, indicating not only that MIDP is not contraindicated in the elderly but even that some postoperative outcomes are better in this subset of patients [16].

Not all elderly patients are the same, and to offer the same surgical approach to each one would be wrong. In particular, the selection of patients is of utmost importance to optimize surgical and oncological outcomes. Several indexes have been elaborated to predict poor postoperative outcomes in elderly patients undergoing pancreatectomy. The Frailty Index [17, 18], and its simplified form, the modified Frailty Index (mFI) [19] proved to predict major complications and mortality after pancreatic surgery effectively $[20,21]$. Of note, it seems that frail patients $(\mathrm{mFI} \geq 1)$ benefit from MIDP, experiencing less severe complications than ODP patients [22].

This study aimed to compare surgical outcomes between MIDP and ODP in elderly patients using propensity-score matching analysis. Secondarily, the efficacy of $\mathrm{mFI}$ in predicting postoperative outcomes of DP elderly patients was evaluated.

\section{Methods}

\section{Study population}

The index population for this study was obtained from the electronic Institutional prospectively maintained database of patients submitted to pancreatic resection at the General and Pancreatic Surgery Unit of the Pancreas Institute of the
University of Verona, Verona, Italy. The database was queried for patients $\geq 70$ years of age submitted to MIDP (index population), either laparoscopic and robot-assisted, with or without splenectomy, for any disease from March 2011 to December 2019. The database was then queried for patients $\geq 70$ years who underwent ODP (control group) during the same period.

\section{Data collected}

Demographic, clinical, surgical, pathological, and postoperative data were extracted. Demographic and clinical variables included age, gender, smoking habit, body mass index (BMI), albumin, hemoglobin, and leukocyte values, presence of diabetes or other relevant comorbidities, American Society of Anesthesiologist Physical Status Classification System (ASA) score, Charlson Age Comorbidity index (CACI) [23]. When the final diagnosis was of malignancy, Ca 19-9 values and neoadjuvant therapy were added. According to the $\mathrm{mFI}$, patients were stratified into non-frail $(\mathrm{mFI}=0)$, mildly frail $(\mathrm{mFI}=1-2)$, or severelyfrail ( $\mathrm{mFI}>2)$, as proposed by Konstantinidis et al. [22]. This stratification was applied to the whole cohort of patients $\geq 70$ years who underwent distal pancreatectomy, and matching was not used due to the small sample size of the MIDP group.

Intraoperative variables included intraoperative blood loss $(\mathrm{mL})$, duration of surgery ( $\mathrm{min}$ ), additional resections (yes/no), conversion to ODP, level of pancreatic transection (pancreatic neck/ gastroduodenal artery level/left aortic border), transection technique (stapler/ultrasonic device/ handsewn), splenic preservation.

Ninety-day postoperative surgical data included pancreatic fistula (POPF) [24], delayed gastric emptying (DGE) [25], post-pancreatectomy hemorrhage (PPH) [26], infected abdominal collections treated with percutaneous drainage or antibiotic therapy, chyle leak [27], surgical site infections (SSI), pulmonary or cardiologic complications, and postoperative confusion. Postoperative pathologic data included final diagnosis, tumor diameter, lymph nodes harvested, lymph node status and the number of metastatic nodes (if any), and R-status.

\section{Surgical procedures}

For the description of the Institutional laparoscopic and robot-assisted techniques adopted, previously published material can be considered [28-30]. The decision to submit patients to MIDP and the choice of the laparoscopic or the robot-assisted approach was mostly made on a collegial basis at a dedicated preoperative surgical meeting [31]. The level of transection was made based on the presumed diagnosis (at the pancreatic neck for malignant or 
Table 1 Preoperative, intraoperative, and pathological data

\begin{tabular}{|c|c|c|c|c|}
\hline \multicolumn{5}{|l|}{ Study Population $N^{\circ}=204$} \\
\hline & Total $\mathrm{n}^{\circ}(\%)$ & Open DP $162(79 \%)$ & MI-DP $42(21 \%)$ & $p$-value \\
\hline \multicolumn{5}{|l|}{ Preoperative data } \\
\hline Age (years, DS) & $74 \pm 4$ & $75 \pm 4$ & $74 \pm 4$ & $\mathbf{0 . 0 3 2}$ \\
\hline Sex (Female) & $108(53 \%)$ & $87(54 \%)$ & $21(50 \%)$ & 0.399 \\
\hline $\mathrm{BMI}\left(\mathrm{Kg} / \mathrm{m}^{2}, \mathrm{DS}\right)$ & $25 \pm 4$ & $25 \pm 4$ & $25 \pm 4$ & 0.567 \\
\hline Previous abdominal surgery & $114(56 \%)$ & $92(57 \%)$ & $22(52 \%)$ & 0.351 \\
\hline ASA score $>$ III & $61(30 \%)$ & $53(33 \%)$ & $8(19 \%)$ & 0.059 \\
\hline Charlson Age $>4$ & $78(38 \%)$ & $68(42 \%)$ & $10(24 \%)$ & 0.022 \\
\hline Neoadjuvant therapy & $30(15 \%)$ & $25(15 \%)$ & $5(12 \%)$ & 0.383 \\
\hline Frailty index $>0$ & $150(74 \%)$ & $120(74 \%)$ & $30(71 \%)$ & 0.433 \\
\hline \multicolumn{5}{|l|}{ Intraoperative data } \\
\hline Spleen preserving & $11(5 \%)$ & $5(3 \%)$ & $6(14 \%)$ & 0.011 \\
\hline Additional resections & $68(33 \%)$ & $59(36 \%)$ & $9(21 \%)$ & 0.046 \\
\hline Vascular resections & $31(15 \%)$ & $28(17 \%)$ & $3(7 \%)$ & 0.076 \\
\hline Transection level & & & & $<0.001$ \\
\hline Pancreatic neck & $165(81 \%)$ & $130(80 \%)$ & $35(83 \%)$ & \\
\hline GDA level & $29(14 \%)$ & $29(18 \%)$ & $0(0 \%)$ & \\
\hline Left aortic border & $10(5 \%)$ & $3(2 \%)$ & $7(17 \%)$ & \\
\hline Management Stump & & & & 0.001 \\
\hline Stapler & $85(44 \%)$ & $67(44 \%)$ & $18(43 \%)$ & \\
\hline Ultrasonic scalpel & $64(33 \%)$ & $42(28 \%)$ & $22(52 \%)$ & \\
\hline Handsewn & $45(23 \%)$ & $43(28 \%)$ & $2(5 \%)$ & \\
\hline Duration of Surgery (minutes, DS) & $260 \pm 93$ & $258 \pm 88$ & $267 \pm 95$ & 0.175 \\
\hline EBL (cc, IQR) & $200[100-400]$ & $250[100-400]$ & $200[150-300]$ & 0.998 \\
\hline \multicolumn{5}{|l|}{ Pathological data } \\
\hline Final Pathology, No. (\%) & & & & $<0.001$ \\
\hline PDAC & $119(58 \%)$ & $102(63 \%)$ & $17(41 \%)$ & \\
\hline pNET & $33(16 \%)$ & $16(10 \%)$ & $17(40 \%)$ & \\
\hline IPMN & $27(13 \%)$ & $23(14 \%)$ & $4(10 \%)$ & \\
\hline $\mathrm{MCN} / \mathrm{SCN}$ & $11(6 \%)$ & $8(5 \%)$ & $3(7 \%)$ & \\
\hline Other & $14(7 \%)$ & $13(8 \%)$ & $1(2 \%)$ & \\
\hline Tumor Size (mm, IQR) & $29[20-45]$ & $30[20-45]$ & $26[18-40]$ & 0.372 \\
\hline Harvest Lymph nodes (IQR) & $28[19-37]$ & 32 [23-40] & 24 [13-33] & 0.001 \\
\hline R0 Status & $159(81 \%)$ & $125(80 \%)$ & $34(81 \%)$ & 0.300 \\
\hline
\end{tabular}

Bold values indicate statistical significance at the $p<0.05$ level

BMI Body mass index; ASA American society of Anesthesiology; EBL Estimated blood loss; PDAC Pancreatic ductal adenocarcinoma; $p N E T$ pancreatic neuroendocrine tumor; IPMN Intraductal pancreatic mucinous neoplasm; $M C N$ Mucinous cystic neoplasm; SCN Serous cystic neoplasm

intermediate-malignant lesion vs. at the projection of the left border of the aorta for benign lesions, when tumor dimensions allowed it). Regarding the technique of transection, two devices were adopted in the vast majority of cases; the triple row stapler reinforced with a PGA felt (NEOVEIL Endo GIA Reinforced Reload with Tri-Staple ${ }^{\circledR}$ Technology $60 \mathrm{~mm}$, Covidien, North Haven, CT, USA), or an ultrasonic scalpel [32, 33]. Typically, for ODP, two Penrose-type capillary drains were placed at the end of the surgery, one close to the pancreatic stump, the other in the splenic fossa. After MIDP, one Penrose-type capillary drain was placed, close to the pancreatic stump and passing through the splenic fossa. When the patient was enrolled in the DIPLOMA trial (MIDP vs. ODP in patients with pancreatic cancer, \#ISRCTN44897265), two drains were placed, one to the left into the splenic fossa and one to the right close to the pancreatic stump. Early drains removal was frequently performed based on the quality and 
Table 2 Postoperative data

\begin{tabular}{|c|c|c|c|c|}
\hline & Total $\mathrm{n}^{\circ}(\%)$ & Open DP $162(79 \%)$ & MI-DP $42(21 \%)$ & $p$-value \\
\hline Any complications & $118(58 \%)$ & $93(57 \%)$ & $25(60 \%)$ & 0.473 \\
\hline POPF & $38(19 \%)$ & $28(17 \%)$ & $10(24 \%)$ & 0.204 \\
\hline Abdominal collections & $70(34 \%)$ & $53(33 \%)$ & $17(41 \%)$ & 0.222 \\
\hline DGE & $5(3 \%)$ & $5(3 \%)$ & $0(0 \%)$ & 0.312 \\
\hline PPH & $25(12 \%)$ & $20(12 \%)$ & $5(12 \%)$ & 0.589 \\
\hline SSI & $18(9 \%)$ & $15(9 \%)$ & $3(7 \%)$ & 0.470 \\
\hline Pulmonary complications & $53(26 \%)$ & $43(27 \%)$ & $10(24 \%)$ & 0.443 \\
\hline Cardiovascular complications & $18(9 \%)$ & $17(11 \%)$ & $1(2 \%)$ & 0.080 \\
\hline Postoperative Confusion & $8(4 \%)$ & $8(5 \%)$ & $0(0 \%)$ & 0.152 \\
\hline ICU Admission & $17(8 \%)$ & $15(9 \%)$ & $2(5 \%)$ & 0.274 \\
\hline Clavien-Dindo $>3$ & $27(13 \%)$ & $22(14 \%)$ & $5(12 \%)$ & 0.503 \\
\hline Length of Stay (days, DS) & $13 \pm 6$ & $15 \pm 6$ & $10 \pm 7$ & 0.042 \\
\hline Reoperations & $11(5 \%)$ & $8(5 \%)$ & $3(7 \%)$ & 0.403 \\
\hline Readmissions & $14(7 \%)$ & $10(6 \%)$ & $4(9 \%)$ & 0.323 \\
\hline Mortality & $2(1 \%)$ & $2(1 \%)$ & $0(0 \%)$ & 0.628 \\
\hline
\end{tabular}

Bold value indicates statistical significance at the $p<0.05$ level

$P O P F$ Postoperative pancreatic fistula; DGE Delayed gastric empty; PPH Post pancreatectomy hemorrhage; $I C U$ Intensive care unit

quantity of the output, its richness in amylase, and the occurrence of postoperative acute pancreatitis [34]. Generally, in the presence of a non-amylase-rich fluid (e.g., $\leq 2000 \mathrm{U} / \mathrm{L}$ ) and the absence of a sinister appearance or postoperative acute pancreatitis, the removal was performed on postoperative day three.

\section{Statistical analysis and case-matching}

According to the normality tests, values were expressed as median and interquartile range, mean and standard deviation (SD), or percentage. Student's t-test, Mann- Whitney U-test, Kruskal-Wallis test, and $\chi^{2}$ test were used as appropriate.

A PSM analysis was performed using the preliminary univariate analysis on the entire cohort. The not balanced variables identified were chosen to compare the MIDP (index) group and the ODP (control) group. The MIDP elderly patients were randomly matched with ODP elderly patients according to a $1: 2$ matching, with a 0.1 caliper and an average treatment effect (ATE), by the approach (MIDP vs. ODP) as the independent variable. Variables considered for propensity score estimation included: age, CACI, splenectomy, additional resections, pancreatic transection level, management of the pancreatic stump, and presence of malignancy at the final pathology. Balance on covariates between MIDP and ODP groups was assessed and reported using absolute standardized differences (ASD) [35]. An ASD value $<0.2$ indicates a small difference between the two groups, identifying an excellent balance. An ASD value between 0.2 and 0.5 shows a difference, implying a good balance. An ASD value between 0.5 and 0.8 indicates a high difference, meaning sub-optimal balance. An ASD value $>0.8$ resulted in a remarkable difference, suggesting a poor balance between the two groups (Supplementary Fig. 1) [36]. Statistical analyses were performed using SPSS software ver. 22 (IBM, Chicago, IL, United States) and R software (R Foundation for Statistical Computing, Vienna, Austria).

\section{Results}

A total of 204 patients aged $\geq 70$ years was submitted to distal pancreatectomy during the study period. Forty-six patients were candidates to receive MIDP, and four $(7.7 \%)$ were converted to open surgery. The preoperative, intraoperative, and pathological data are shown in Table 1. The two groups resulted imbalanced in age, CACI, splenectomy, additional resections, pancreatic transection level, management of the pancreatic stump, and presence of malignancy at the final pathology $(p<0.05)$.

The postoperative outcomes of the series are outlined in Table 2. The postoperative clinical course of the entire cohort was comparable $(p>0.05)$. Notably, the ODP group had a higher mean length of stay than the MIDP (15 vs. 10 days, respectively, $p=0.042$ ). 
Table 3 Preoperative, intraoperative, and pathological data after propensity score matching

\begin{tabular}{|c|c|c|c|c|}
\hline \multicolumn{5}{|l|}{ Study Population $\mathrm{N}^{\circ}=120$} \\
\hline & Total $\mathrm{n}^{\circ}(\%)$ & Open DP $80(67 \%)$ & MI-DP $40(33 \%)$ & $p$-value \\
\hline \multicolumn{5}{|l|}{ Preoperative } \\
\hline Age (years, DS) & $74 \pm 3$ & $74 \pm 4$ & $73 \pm 3$ & 0.127 \\
\hline Sex (Female) & $64(53 \%)$ & $43(53 \%)$ & $21(54 \%)$ & 0.547 \\
\hline BMI $\left(\mathrm{Kg} / \mathrm{m}^{2}, \mathrm{DS}\right)$ & $25 \pm 4$ & $25 \pm 4$ & $25 \pm 4$ & 0.720 \\
\hline Previous abdominal surgery & $65(54 \%)$ & $45(55 \%)$ & $20(51 \%)$ & 0.403 \\
\hline ASA score $>$ III & $29(24 \%)$ & $22(27 \%)$ & $7(18 \%)$ & 0.191 \\
\hline Charlson Age $>4$ & $34(28 \%)$ & $26(32 \%)$ & $8(21 \%)$ & 0.134 \\
\hline Neoadjuvant therapy & $19(16 \%)$ & $14(17 \%)$ & $5(13 \%)$ & 0.367 \\
\hline Frailty index $>0$ & $87(73 \%)$ & $59(73 \%)$ & $28(72 \%)$ & 0.534 \\
\hline \multicolumn{5}{|l|}{ Intraoperative } \\
\hline Spleen preserving & $11(9 \%)$ & $5(6 \%)$ & $6(15 \%)$ & 0.099 \\
\hline Additional resection & $30(25 \%)$ & $23(28 \%)$ & $7(18 \%)$ & 0.156 \\
\hline Vascular resection & $15(13 \%)$ & $12(15 \%)$ & $3(8 \%)$ & 0.212 \\
\hline Transection level & & & & 0.005 \\
\hline Pancreatic neck & $111(93 \%)$ & $78(98 \%)$ & $33(82 \%)$ & \\
\hline Left aortic border & $9(7 \%)$ & $2(2 \%)$ & $7(18 \%)$ & \\
\hline Management Stump & & & & 0.099 \\
\hline Stapler & $64(53 \%)$ & $47(58 \%)$ & $17(44 \%)$ & \\
\hline Ultrasonic scalpel & $56(47 \%)$ & $33(42 \%)$ & $23(56 \%)$ & \\
\hline Duration of Surgery (minutes, DS) & $261 \pm 92$ & $252 \pm 86$ & $261 \pm 84$ & 0.166 \\
\hline $\mathrm{EBL}(\mathrm{cc}, \mathrm{IQR})$ & $250[100-400]$ & $265[100-400]$ & $200[150-300]$ & 0.101 \\
\hline \multicolumn{5}{|l|}{ Pathological } \\
\hline Final Pathology, No. (\%) & & & & 0.071 \\
\hline PDAC & $60(50 \%)$ & $43(53 \%)$ & $16(43 \%)$ & \\
\hline pNET & $25(21 \%)$ & $9(12 \%)$ & $16(40 \%)$ & \\
\hline IPMN & $15(13 \%)$ & $12(15 \%)$ & $3(7 \%)$ & \\
\hline $\mathrm{MCN} / \mathrm{SCN}$ & $8(7 \%)$ & $5(6 \%)$ & $3(7 \%)$ & \\
\hline Other & $12(9 \%)$ & $11(14 \%)$ & $1(3 \%)$ & \\
\hline Tumor Size (mm, IQR) & $27[20-40]$ & $30[20-40]$ & $24[18-33]$ & 0.238 \\
\hline Harvest Lymph nodes (IQR) & $25[16-34]$ & 26 [19-39] & 25 [13-32] & 0.054 \\
\hline R0 Status & $103(86 \%)$ & $70(88 \%)$ & $33(83 \%)$ & 0.473 \\
\hline
\end{tabular}

Bold value indicates statistical significance at the $p<0.05$ level

$B M I$ Body mass index; ASA American society of Anesthesiology; EBL Estimated blood loss; PDAC Pancreatic ductal adenocarcinoma; $p N E T$ pancreatic neuroendocrine tumor; IPMN Intraductal pancreatic mucinous neoplasm; $M C N$ Mucinous cystic neoplasm; SCN Serous cystic neoplasm

After matching, 40 and 80 patients constituted the MIDP group and ODP group, respectively.

\section{MIDP versus ODP after matching: baseline, surgical, pathology, and postoperative results}

No differences were found in the patients' baseline characteristics between MIDP and ODP groups after propensity score weighting was found (Table 3). The pancreatic transection was more frequently on the left aortic border in the MIDP group $(p=0.005)$.
None of the postoperative variables considered stratified differently from a statistical standpoint between the two groups (Table 4). Remarkably, the ODP group still had a higher mean length of stay than the MIDP (16 vs. 10 days, respectively, $p=0.046$ ).

\section{Baseline, surgical, and pathology results and postoperative outcome according to $\mathrm{mFI}$}

Among the baseline features, BMI and ASA score were higher in severely frail patients $(p=0.001$ and $p<0.001$, 
Table 4 Postoperative outcomes after propensity score matching

\begin{tabular}{|c|c|c|c|c|}
\hline \multicolumn{5}{|l|}{ Study Population $\mathrm{N}^{\circ}=120$} \\
\hline & Total $\mathrm{n}^{\circ}(\%)$ & Open DP $80(67 \%)$ & MI-DP $40(33 \%)$ & $p$-value \\
\hline Any complications & $71(59 \%)$ & $48(59 \%)$ & $23(59 \%)$ & 0.565 \\
\hline POPF & $25(21 \%)$ & $16(20 \%)$ & $9(24 \%)$ & 0.396 \\
\hline Abdominal collections & $46(38 \%)$ & $30(37 \%)$ & $16(41 \%)$ & 0.411 \\
\hline DGE & $4(3 \%)$ & $4(5 \%)$ & $0(0 \%)$ & 0.203 \\
\hline $\mathrm{PPH}$ & $16(13 \%)$ & $11(14 \%)$ & $5(13 \%)$ & 0.578 \\
\hline SSI & $11(9 \%)$ & $8(10 \%)$ & $3(8 \%)$ & 0.493 \\
\hline Pulmonary complications & $29(24 \%)$ & $20(25 \%)$ & $9(23 \%)$ & 0.519 \\
\hline Cardiovascular complications & $10(8 \%)$ & $9(11 \%)$ & $1(3 \%)$ & 0.104 \\
\hline Postoperative Confusion & $3(3 \%)$ & $3(4 \%)$ & $0(0 \%)$ & 0.304 \\
\hline ICU Admission & $8(7 \%)$ & $6(7 \%)$ & $2(5 \%)$ & 0.486 \\
\hline Clavien-Dindo $>3$ & $16(13 \%)$ & $12(15 \%)$ & $4(10 \%)$ & 0.353 \\
\hline Length of Stay (days, DS) & $13 \pm 14$ & $16 \pm 20$ & $10 \pm 7$ & 0.046 \\
\hline Reoperations & $7(6 \%)$ & $5(6 \%)$ & $2(5 \%)$ & 0.590 \\
\hline Readmissions & $10(8 \%)$ & $6(8 \%)$ & $4(10 \%)$ & 0.425 \\
\hline Mortality & $1(1 \%)$ & $1(1 \%)$ & $0(0 \%)$ & 0.672 \\
\hline
\end{tabular}

Bold value indicates statistical significance at the $p<0.05$ level

$P O P F$ Postoperative pancreatic fistula; DGE Delayed gastric empty; PPH Post pancreatectomy hemorrhage; $I C U$ Intensive care unit

respectively), as shown in Table 5. Surgery's duration increased as the severity of frailty did $(p=0.013)$. No differences were found in pathology data among the three groups.

Increasing and statistically significant rates of many complications were found among the three groups, where the severely frail patients worsen, compared to mildly frail and no frail ones (Table 6). In particular, this refers to any complication ( $76 \%$ vs. $60 \%$ vs. $44 \%, p=0.022)$, abdominal collection ( $52 \%$ vs. $37 \%$ vs. $20 \%, p=0.014)$, pulmonary complication $(54 \%$ vs. $24 \%$ vs. $17 \%, p=0.001)$, postoperative confusion ( $12 \%$ vs. $3 \%$ vs. $2 \%, p=0.047)$, and Clavien-Dindo severity $\geq 3$ events ( $24 \%$ vs. $14 \%$ vs. $6 \%, p=0.036$ ). The length of stay was significantly longer in severely frail patients (16 vs. 13 vs. 12 days, $p=0.018$ ).

\section{Discussion}

Reduced functional reserve and stress response and high prevalence of comorbidities are typical features of the elderly. Thus, this population of patients may benefit the most from minimally invasive surgery. However, only four reports compared surgical outcomes of MIDP versus ODP in elderly patients [12-15]. All studies concluded that MIDP is at least as safe as ODP. These results were pooled in a meta-analysis that reported an overall benefit for MIDP over ODP regarding length of stay and intraoperative blood loss [16]. The results of this study corroborate these previous findings, namely that MIDP in elderly patients can be safely performed, as no differences were found in terms of postoperative outcomes. In particular, major complications, surgical and non-surgical complications (e.g., cardiopulmonary events) occurred homogeneously between the index and control groups, and the length of stay was similar. It must be noted that this study's findings are the result of a careful selection of cases to treat with MIDP, deriving from proper preoperative evaluation and collegial discussion.

Noteworthily, the duration of hospitalization of MIDP patients (median 8, IQR 7-12) was lower than the one institutionally reported for MIDP (10 days, IQR 6-10), deriving from a cohort of 103 patients with a mean age of 52 years [IQR 40-62]) [37]. This finding gain strength considering that all patients are discharged home in our institution rather than going to health care facilities. So, a patient goes home when the spouse or the relatives/caregivers (usually the children) are ready to accommodate him, which may take longer when the patient is elderly.

Despite desirable, a preoperative geriatric assessment may not be feasible for each elder patient. Thus, the possibility to use the mFI to identify elderly patients at higher risk of postoperative complications is an interesting opportunity. After applying the $\mathrm{mFI}$ to the whole cohort of patients $\geq 70$ years submitted to DP, the baseline features analysis showed that BMI was proportionally higher for mildly and severely frail patients than non-frail ones. They were also more frequently classified as ASA $\geq 3$, probably 
Table 5 Stratification of the study population according to the modified Frailty Index

\begin{tabular}{|c|c|c|c|c|}
\hline \multicolumn{5}{|l|}{ Study Population $\mathrm{N}^{\circ}=204$} \\
\hline & No Frail $54(26 \%)$ & Mildly Frail 125 (26\%) & Severely Frail $25(74 \%)$ & $p$-value \\
\hline \multicolumn{5}{|l|}{ Preoperative data } \\
\hline Age (years, DS) & $75 \pm 4$ & $75 \pm 4$ & $75 \pm 4$ & 0.897 \\
\hline Sex (Female) & $33(61 \%)$ & $65(52 \%)$ & $10(40 \%)$ & 0.205 \\
\hline BMI $\left(\mathrm{Kg} / \mathrm{m}^{2}, \mathrm{DS}\right)$ & $23 \pm 3$ & $25 \pm 4$ & $26 \pm 4$ & 0.001 \\
\hline Previous abdominal surgery & $33(61 \%)$ & $66(53 \%)$ & $15(60 \%)$ & 0.535 \\
\hline ASA score $>$ III & $7(13 \%)$ & $35(28 \%)$ & $19(76 \%)$ & $<0.001$ \\
\hline Neoadjuvant therapy & $5(9 \%)$ & $19(15 \%)$ & $6(24 \%)$ & 0.221 \\
\hline \multicolumn{5}{|l|}{ Intraoperative data } \\
\hline Spleen preserving & $3(6 \%)$ & $7(6 \%)$ & $1(4 \%)$ & 0.947 \\
\hline Additional resections & $17(32 \%)$ & $38(30 \%)$ & $13(52 \%)$ & 0.106 \\
\hline Vascular resections & $9(17 \%)$ & $17(14 \%)$ & $5(20 \%)$ & 0.675 \\
\hline Transection level & & & & 0.387 \\
\hline Pancreatic neck & $44(82 \%)$ & $101(81 \%)$ & $20(80 \%)$ & \\
\hline GDA level & $5(9 \%)$ & $20(16 \%)$ & $4(16 \%)$ & \\
\hline Left aortic border & $5(9 \%)$ & $4(3 \%)$ & $1(4 \%)$ & \\
\hline Management Stump & & & & 0.924 \\
\hline Stapler & $21(40 \%)$ & $52(45 \%)$ & $12(50 \%)$ & \\
\hline Ultrasonic scalpel & $18(34 \%)$ & $39(33 \%)$ & $7(29 \%)$ & \\
\hline Handsewn & $14(26 \%)$ & $26(22 \%)$ & $5(21 \%)$ & \\
\hline Duration of Surgery (minutes, DS) & $224 \pm 64$ & $271 \pm 93$ & $297 \pm 101$ & 0.013 \\
\hline $\mathrm{EBL}(\mathrm{cc}, \mathrm{IQR})$ & $200[100-350]$ & $250[200-320]$ & $260[220-355]$ & 0.565 \\
\hline \multicolumn{5}{|l|}{ Pathological data } \\
\hline Final Pathology, No. (\%) & & & & 0.414 \\
\hline PDAC & $31(58 \%)$ & $71(57 \%)$ & $17(68 \%)$ & \\
\hline pNET & $12(22 \%)$ & $17(14 \%)$ & $4(16 \%)$ & \\
\hline IPMN & $5(9 \%)$ & $19(15 \%)$ & $3(12 \%)$ & \\
\hline $\mathrm{MCN} / \mathrm{SCN}$ & $1(2 \%)$ & $10(8 \%)$ & $0(0 \%)$ & \\
\hline Other & $5(9 \%)$ & $8(6 \%)$ & $1(4 \%)$ & \\
\hline Tumor Size (mm, IQR) & $30[22-50]$ & $25[20-40]$ & $28[20-45]$ & 0.799 \\
\hline
\end{tabular}

Bold values indicate statistical significance at the $p<0.05$ level

$B M I$ Body mass index; ASA American society of Anesthesiology; EBL Estimated blood loss; PDAC Pancreatic ductal adenocarcinoma; $p N E T$ pancreatic neuroendocrine tumor; IPMN Intraductal pancreatic mucinous neoplasm; $M C N$ Mucinous cystic neoplasm; SCN Serous cystic neoplasm

due to more systemic diseases (e.g., diabetes, hypertension, cardiovascular problems). The duration of surgery increased proportionally to the grade of frailty. We do not have an explanation for this. This may be due to the surgeon's attitude toward performing a more precise and safe surgery in the presence of a severely frail patient, which carries serious comorbidities. However, this is just speculation.

As already reported [22, 38], the mFI predicted some postoperative complications and, in general, a worse postoperative course, as demonstrated by a longer length of stay. In detail, higher rates of any complication, abdominal collection, and Clavien-Dindo $\geq 3$ complications were found in mild and severely frail patients, compared to nonfrail ones. Noteworthily, the mFI also predicted non-surgical postoperative complications, such as postoperative confusion and pulmonary complications. These results show that surgical and non-surgical risk prediction may be obtained using an easy tool such as the mFI.

It must be noted that, interestingly, after DP, some postoperative complications, such as pancreatic fistula, post-pancreatectomy hemorrhage, and the reoperation rate, are not superior in frail patients. We believe that they are hardly favored by the cardiovascular comorbidities and the poor functional reserve that may be present in a frail patient. Rather, they are the result of properly pancreas- 
Table 6 Postoperative outcomes of the series stratified according to the modified Frailty Index

\begin{tabular}{|c|c|c|c|c|}
\hline \multicolumn{5}{|l|}{ Study Population $\mathrm{N}^{\circ}=204$} \\
\hline & No Frailty $54(26 \%)$ & Mild Frailty $125(26 \%)$ & Severe Frailty $25(74 \%)$ & $p$-value \\
\hline Any complications & $24(44 \%)$ & $75(60 \%)$ & $19(76 \%)$ & 0.022 \\
\hline POPF & $7(13 \%)$ & $27(22 \%)$ & $4(16 \%)$ & 0.824 \\
\hline Abdominal collections & $11(20 \%)$ & $46(37 \%)$ & $13(52 \%)$ & 0.014 \\
\hline DGE & $0(0 \%)$ & $4(3 \%)$ & $1(4 \%)$ & 0.387 \\
\hline PPH & $5(9 \%)$ & $16(13 \%)$ & $4(16 \%)$ & 0.667 \\
\hline SSI & $5(9 \%)$ & $10(8 \%)$ & $3(12 \%)$ & 0.806 \\
\hline Pulmonary complications & $9(17 \%)$ & $30(24 \%)$ & $14(54 \%)$ & 0.001 \\
\hline Cardiovascular complications & $1(2 \%)$ & $14(11 \%)$ & $3(12 \%)$ & 0.108 \\
\hline Postoperative Confusion & $1(2 \%)$ & $4(3 \%)$ & $3(12 \%)$ & 0.047 \\
\hline ICU Admission & $2(4 \%)$ & $12(10 \%)$ & $3(12 \%)$ & 0.327 \\
\hline Clavien-Dindo $>3$ & $3(6 \%)$ & $18(14 \%)$ & $6(24 \%)$ & 0.036 \\
\hline Length of Stay (days, DS) & $12 \pm 6$ & $13 \pm 9$ & $16 \pm 12$ & 0.018 \\
\hline Reoperations & $2(4 \%)$ & $7(6 \%)$ & $2(8 \%)$ & 0.724 \\
\hline Readmissions & $4(7 \%)$ & $7(6 \%)$ & $3(12 \%)$ & 0.512 \\
\hline Mortality & $0(0 \%)$ & $2(2 \%)$ & $0(0 \%)$ & 0.525 \\
\hline
\end{tabular}

Bold values indicate statistical significance at the $p<0.05$ level

$P O P F$ Postoperative pancreatic fistula; DGE Delayed gastric empty; $P P H$ Post pancreatectomy hemorrhage; $I C U$ Intensive care unit

and surgery-specific factors (e.g., pancreatic texture, transection technique, level of transection, and drain management policy).

In general, our findings demonstrate that MIDP is not inferior to ODP in selected elderly patients, and that fragile elderly patients are at higher risk for postoperative complications after DP, with a proportionate increase. In the absence of a geriatric assessment, the application of the mFI may be useful to identify patients to whom dedicate tailored perioperative management to improve the postoperative outcome (e.g., nutritional assessment and intervention, pre-habilitation, routine access to intensive care unit after surgery). We deliberately choose not to include the mFI among the crucial variables in the PSM since previous literature on $\mathrm{mFI}$ and distal pancreatectomy was not robust enough. The present results give consistency to $\mathrm{mFI}$ as a variable to include in the baseline assessment of elderly patients receiving DP.

This manuscript's strength is that for the first time, the comparison between MIDP and ODP in elderly patients was performed through a propensity score matching to reduce the selection bias. This study is also the first to apply the mFI to a single-center, homogeneous cohort of elderly patients undergoing DP (the report by Konstantinidis et al. [22] is a registry-based study). Some limitations may flaw the results and the considerations: (i) the sample size of elderly who underwent MIDP is small; (ii) a selection bias (the percentage of elderly submitted to MIDP is approximately only 20 percent of the total of elderly underwent DP during the study period).

To conclude, MIDP in elderly patients seems to be safe in experienced hands and high-volume centers. Fragile $(\mathrm{mFI}>0)$ elderly patients undergoing DP are more prone to experience postoperative complications, longer hospitalization, and worse postoperative course as the mFI increases. Age per sé is not an expression of poor functional reserve or difficult recovery after surgery. Age and frailty, instead, can be so.

Funding This research did not receive any specific grant from funding agencies in the public, commercial, or not-for-profit sectors.

\section{Declarations}

Conflict of interest The authors declare that they have no conflict of interest.

Ethical approval The institutional review board approved the study (approval number for the retrospective data collection, PAD-R \#1101CESC).

Supplementary Information The online version contains supplementary material available at https://doi.org/10.1007/s00268021-06436-2.

Open Access This article is licensed under a Creative Commons Attribution 4.0 International License, which permits use, sharing, adaptation, distribution and reproduction in any medium or format, as long as you give appropriate credit to the original author(s) and the 
source, provide a link to the Creative Commons licence, and indicate if changes were made. The images or other third party material in this article are included in the article's Creative Commons licence, unless indicated otherwise in a credit line to the material. If material is not included in the article's Creative Commons licence and your intended use is not permitted by statutory regulation or exceeds the permitted use, you will need to obtain permission directly from the copyright holder. To view a copy of this licence, visit http://creativecommons. org/licenses/by/4.0/.

\section{References}

1. de Rooij T, van Hilst J, van Santvoort H et al (2019) Minimally invasive versus open distal pancreatectomy (LEOPARD): a multicenter patient-blinded randomized controlled trial. Ann Surg 269:2-9

2. Klompmaker S, de Rooij T, Koerkamp BG et al (2021) International validation of reduced major morbidity after minimally invasive distal pancreatectomy compared with open pancreatectomy. Ann Surg 274:e966-e973

3. Esposito A, Balduzzi A, De Pastena M et al (2019) Minimally invasive surgery for pancreatic cancer. Expert Rev Anticancer Ther 19:947-958

4. Salomon JA, Wang H, Freeman MK et al (2012) Healthy life expectancy for 187 countries, 1990-2010: a systematic analysis for the Global Burden Disease Study 2010. Lancet 380:2144-2162

5. Crimmins EM (2015) Lifespan and Healthspan: Past, Present, and Promise. Gerontologist 55:901-911

6. Sukharamwala P, Thoens J, Szuchmacher M et al (2012) Advanced age is a risk factor for post-operative complications and mortality after a pancreaticoduodenectomy: a meta-analysis and systematic review. HPB (Oxford) 14:649-657

7. Oliveira-Cunha M, Malde DJ, Aldouri A et al (2013) Results of pancreatic surgery in the elderly: is age a barrier? HPB (Oxford) $15: 24-30$

8. Paiella S, De Pastena M, Pollini T et al (2017) Pancreaticoduodenectomy in patients $>/=75$ years of age: are there any differences with other age ranges in oncological and surgical outcomes? Results from a tertiary referral center. World J Gastroenterol 23:3077-3083

9. Brahmbhatt B, Bhurwal A, Lukens FJ et al (2016) Pancreatic surgery in the older population: a single institution's experience over two decades. Curr Gerontol Geriatr Res 2016:8052175

10. Aoyama T, Murakawa M, Atsumi Y et al (2016) The short- and long-term outcomes of pancreatic resection for pancreatic adenocarcinoma in patients older than 75 years. Int Surg 101:554-561

11. Chapman BC, Gajdos C, Hosokawa P et al (2018) Comparison of laparoscopic to open pancreaticoduodenectomy in elderly patients with pancreatic adenocarcinoma. Surg Endosc 32:2239-2248

12. Chen K, Pan Y, Mou YP et al (2019) Surgical outcomes of laparoscopic distal pancreatectomy in elderly and octogenarian patients: a single-center, comparative study. Surg Endosc 33:2142-2151

13. Aprea G, De Rosa D, Milone M et al (2017) Laparoscopic distal pancreatectomy in elderly patients: is it safe? Aging Clin Exp Res 29:41-45

14. Sahakyan MA, Edwin B, Kazaryan AM et al (2017) Perioperative outcomes and survival in elderly patients undergoing laparoscopic distal pancreatectomy. J Hepatobiliary Pancreat Sci $24: 42-48$
15. Souche R, Fuks D, Perinel J et al (2018) Impact of laparoscopy in patients aged over 70 years requiring distal pancreatectomy: a French multicentric comparative study. Surg Endosc 32:3164-3173

16. van der Heijde N, Balduzzi A, Alseidi A et al (2020) The role of older age and obesity in minimally invasive and open pancreatic surgery: a systematic review and meta-analysis. Pancreatology 20:1234-1242

17. Mitnitski AB, Mogilner AJ, Rockwood K (2001) Accumulation of deficits as a proxy measure of aging. ScientificWorldJournal $1: 323-336$

18. Rockwood K, Song X, MacKnight C et al (2005) A global clinical measure of fitness and frailty in elderly people. CMAJ 173:489-495

19. Velanovich V, Antoine H, Swartz A et al (2013) Accumulating deficits model of frailty and postoperative mortality and morbidity: its application to a national database. J Surg Res 183:104-110

20. Augustin T, Burstein MD, Schneider EB et al (2016) Frailty predicts risk of life-threatening complications and mortality after pancreatic resections. Surgery 160:987-996

21. Mogal H, Vermilion SA, Dodson R et al (2017) Modified frailty index predicts morbidity and mortality after pancreaticoduodenectomy. Ann Surg Oncol 24:1714-1721

22. Konstantinidis IT, Lewis A, Lee B et al (2017) Minimally invasive distal pancreatectomy: greatest benefit for the frail. Surg Endosc 31:5234-5240

23. Charlson M, Szatrowski TP, Peterson J et al (1994) Validation of a combined comorbidity index. J Clin Epidemiol 47:1245-1251

24. Bassi C, Marchegiani G, Dervenis C et al (2017) The 2016 update of the International Study Group (ISGPS) definition and grading of postoperative pancreatic fistula: 11 Years After. Surgery 161:584-591

25. Wente MN, Bassi C, Dervenis C et al (2007) Delayed gastric emptying (DGE) after pancreatic surgery: a suggested definition by the International Study Group of Pancreatic Surgery (ISGPS). Surgery 142:761-768

26. Wente MN, Veit JA, Bassi C et al (2007) Postpancreatectomy hemorrhage (PPH): an International study group of pancreatic surgery (ISGPS) definition. Surgery 142:20-25

27. Besselink MG, van Rijssen LB, Bassi C et al (2017) Definition and classification of chyle leak after pancreatic operation: a consensus statement by the International study group on pancreatic surgery. Surgery 161:365-372

28. Melotti G, Butturini G, Piccoli M et al (2007) Laparoscopic distal pancreatectomy: results on a consecutive series of 58 patients. Ann Surg 246:77-82

29. Butturini G, Damoli I, Crepaz L et al (2015) A prospective nonrandomised single-center study comparing laparoscopic and robotic distal pancreatectomy. Surg Endosc 29:3163-3170

30. Esposito A, Casetti L, De Pastena M et al (2021) Robotic spleenpreserving distal pancreatectomy: the Verona experience. Updates Surg 73:923-928

31. Surci N, Ramera M, Borin A et al (2020) Implementation of a strategic preoperative surgical meeting to improve the level of care at a high-volume pancreatic center: a before-after analysis of 1000 consecutive cases. Updates Surg 72:155-161

32. Pulvirenti A, Landoni L, Borin A et al (2019) Reinforced stapler versus ultrasonic dissector for pancreatic transection and stump closure for distal pancreatectomy: A propensity matched analysis. Surgery 166:271-276

33. Landoni L, De Pastena M, Fontana M, et al (2021) A randomized controlled trial of stapled versus ultrasonic transection in distal pancreatectomy. Surg Endosc; doi: https://doi.org/10.1007/ s00464-021-08724-3. Online ahead of print 
34. Andrianello S, Bannone E, Marchegiani G et al (2020) Characterization of postoperative acute pancreatitis (POAP) after distal pancreatectomy. Surgery 169:724-731

35. Ali MS, Groenwold RH, Belitser SV et al (2015) Reporting of covariate selection and balance assessment in propensity score analysis is suboptimal: a systematic review. J Clin Epidemiol 68:112-121

36. Cohen J (1988) Statistical power analysis for the behavioral sciences. Routledge, New York

37. De Pastena M, Esposito A, Paiella S et al (2020) Cost-effectiveness and quality of life analysis of laparoscopic and robotic distal pancreatectomy: a propensity score-matched study. Surg Endosc 35:1420-1428

38. Mosquera C, Spaniolas K, Fitzgerald TL (2016) Impact of frailty on surgical outcomes: The right patient for the right procedure. Surgery 160:272-280

Publisher's Note Springer Nature remains neutral with regard to jurisdictional claims in published maps and institutional affiliations. 